\title{
Sol-gel chemistry mediated Zn/Al-based complex dispersant for SWCNT in water without foam formation
}

Radovan Kukobat $^{\text {a,b }}$, Daiki Minami ${ }^{b}$, Takuya Hayashi ${ }^{a}$, Yoshiyuki Hattori ${ }^{\mathrm{c}}$, Takafumi Matsuda ${ }^{\mathrm{d}}$, Motoo Sunaga ${ }^{\mathrm{d}}$, Bhuvnesh Bharti ${ }^{\mathrm{e}}$, Kiyotaka Asakura ${ }^{\mathrm{f}}$, and Katsumi Kaneko ${ }^{\text {,** }}$

${ }^{a}$ Department of Electrical Engineering, Shinshu University, Nagano 380-8553, Japan

${ }^{\mathrm{b}}$ Center for Energy and Environmental Science, Nagano 380-8553, Japan

${ }^{c}$ Division of Chemistry and Materials, Faculty of Textile Science and Technology, Shinshu University, Ueda 386-8567, Japan

${ }^{\mathrm{d}}$ Technical Center, Fuji Chemical Co. Nakatsugawa 509-9132, Japan

${ }^{\mathrm{e}}$ Department of Chemical and Biomolecular Engineering, North Carolina State University, Raleigh, NC, USA

${ }^{\mathrm{f}}$ Catalysis Research Center, Hokkaido University, Sapporo 001-0021, Japan

* Corresponding author. Tel: +81 (0)26 269 5743. E-mail: kkaneko@ shinshu-u.ac.jp (Katsumi Kaneko) 


\section{ABSTRACT}

We report a bimetallic $\mathrm{Zn} / \mathrm{Al}$ complex as an efficient inorganic dispersant for SWCNT, synthesized from $\mathrm{Zn}\left(\mathrm{CH}_{3} \mathrm{COO}\right)_{2}$ and $\mathrm{Al}\left(\mathrm{NO}_{3}\right)_{3}$. The $\mathrm{Zn} / \mathrm{Al}$ complex shows more than four times greater efficiency at dispersing SWCNT than widely used surfactants (CTAB and SDS). Besides remarkable dispersibility, the $\mathrm{Zn} / \mathrm{Al}$ complex does not foam upon any shaking treatment and it can be used just after quick dissolution of the powdered form, which is a marked advantage over surfactants. The $\mathrm{Zn} / \mathrm{Al}$ complex, containing amorphous $\mathrm{Al}\left(\mathrm{CH}_{3} \mathrm{COO}\right)_{3}$ and a complex of $\mathrm{Zn}^{2+}$ and $\mathrm{NO}_{3}^{-} \mathrm{NO}_{3}^{-}$ions, should have a unique dispersion mechanism, differing from the surfactants. $\mathrm{Al}\left(\mathrm{CH}_{3} \mathrm{COO}\right)_{3}$ has higher affinity for SWCNT than ions, adsorbing onto their surface in the first layer and attracting $\mathrm{Zn}^{2+}$ and $\mathrm{NO}_{3}^{-}$ions. Charge transfer interactions between the $\mathrm{Zn} / \mathrm{Al}$ complex and SWCNT as evidenced by optical absorption spectroscopy should induce a charge on SWCNT; the zeta potential of such coated SWCNT was $+55 \mathrm{mV}$, which is in agreement with the high stability of SWCNT in water. Hence, the Zn/Al complex can widen the applications of SWCNT to various technologies such as the transparent and conductive films, as well as high performance composite polymers.

\section{Introduction}

Single-wall carbon nanotubes [1] (SWCNT) are known to possess outstanding physical and chemical properties such as high electrical and thermal conductivities, photo luminescence, and mechanical properties [2-5]. However, pure SWCNT form firm bundles [6], which hampers their application to various technologies. Hence, it is indispensable to dissociate the bundles to make use of the outstanding properties of SWCNT. Non-covalent methods using surfactants $[7,8]$ and polymers [9,10], and covalent chemical functionalization [11] have been widely used to disrupt the bundle structures in aqueous media. One of the major drawbacks of using surfactants and polymers is foam formation, which is not environmentally friendly, causing serious hurdles in industrial application [12,13]. Chemical functionalization, which is quite efficient for dispersing SWCNT, affects their electronic properties due to $\mathrm{sp}^{3}$ hybridization of C-atoms [14], diminishing electrical conductivity, which is a disadvantage of this method. Recent supermolecular chemistry approaches have offered a powerful route for the reversible and controllable dispersion of SWCNT $[15,16]$. However, there has been little research on inorganic dispersants for SWCNT; our preceding study showed that nanosilica can disperse SWCNT, but loses its 
dispersibility over time [17]. Thus, the inorganic SWCNT dispersant of sufficient stability should offer a new application field of SWCNT.

Sol-gel chemistry has been used in energy-saving ceramics processing. The sol-gel method enables us to prepare powders, thin films, and fibers of metal oxides and/or hydroxides $[18,19]$. This suggests that sol-gel agents can form intermediate self-assembly oxophilic structures, depending on the precursors of the process. We hypothesized that the self-assembly structures in sol-gel chemistry [20,21] can play a role as dispersants for SWCNT. The dispersion stability arises from electrostatic repulsive interactions between charged SWCNT [22]. Bimetallic sol-gel agents of mixed valence should be promising for the dispersion of SWCNT. A systematic study of bimetallic sol-gel agents lead to a $\mathrm{Zn} / \mathrm{Al}$ complex as an outstanding dispersant for SWCNT. This paper reports high dispersion of highly crystalline SWCNT (Fig. S1) with an order bundle structure (Fig. S2), aided by a bimetallic Zn/Al complex, including its dispersion mechanism as well.

\section{Experimental}

\subsection{Carbon nanotube samples and preparation of bimetallic complexes}

We used highly pure and crystalline SWCNT (Meijo) prepared by arc method [23] as

delivered without any future purification; the SWCNT samples were used for the dispersion experiments without any pre-treatment. $\mathrm{Zn} / \mathrm{Al}$ complex was prepared by the sol-gel method using $\mathrm{Zn}\left(\mathrm{CH}_{3} \mathrm{COO}\right)_{2}$ and $\mathrm{Al}\left(\mathrm{NO}_{3}\right)_{3} .1 \mathrm{~g}$ of the reaction mixture with a molar fraction of $\mathrm{Zn}$ of 0.66 and $\mathrm{Al}$ of 0.34 was dissolved in distilled water of $20 \mathrm{~g}$, and the reaction was conducted in an oil bath with reflux at $373 \mathrm{~K}$ for $2 \mathrm{~h}$. After the reaction, the solvent was evaporated using a rotary evaporator, and a viscous colorless liquid was obtained. The obtained product was dried in a vacuum oven for $3 \mathrm{~h}$ at $373 \mathrm{~K}$ to yield the solidified $\mathrm{Zn} / \mathrm{Al}$ complex.

We chose $\mathrm{Zn}\left(\mathrm{CH}_{3} \mathrm{COO}\right)_{2}$ and $\mathrm{Al}\left(\mathrm{NO}_{3}\right)_{3}$ for the best bimetallic complex through qualitative dispersion testing of different combinations of nitrates of $\mathrm{Al}, \mathrm{Fe}, \mathrm{Co}, \mathrm{Ag}, \mathrm{Gd}, \mathrm{Cu}, \mathrm{Ni}$, $\mathrm{Mg}, \mathrm{Ca}, \mathrm{Li}$, and $\mathrm{K}$ with $\mathrm{Zn}\left(\mathrm{CH}_{3} \mathrm{COO}\right)_{2}$ at certain molar ratios.

\subsection{Evaluation of dispersibility}

SWCNT of $0.50 \mathrm{mg}$ were dispersed in $25 \mathrm{~g}$ of aqueous solution containing dispersants of the different concentration, from 0.001 to $1.000 \mathrm{wt}$ \%, with ultrasonic treatment for $20 \mathrm{~min}$ using 
a homogenizer tip (SONIC, VS 505) of $150 \mathrm{~W}$ and $20 \mathrm{kHz}$. The dispersibility was evaluated using a calibration curve of the optical absorbance against the SWCNT concentration with an optical absorption spectrometer (JASCO, V 670); the standard calibration curve was obtained using cetyltrimethylammonium bromide (CTAB) as shown in Fig. S3. It is important to note that the dispersibility was expressed as relative wt.\% of dispersed SWCNT, having values from 0 to 100 wt.\%. Relative wt.\% of dispersed SWCNT is a ratio of the amount of SWCNT in the supernatant (determined from the calibration curve, Fig. S3) and the total amount of SWCNTs in the system.

\subsection{Structural characterization of the $\mathrm{Zn} / \mathrm{Al}$ complex}

The solid complex was characterized with X-ray diffraction (XRD) using a Bruker X-ray diffractometer with $\mathrm{CuK} \alpha$, X-ray photoelectron spectroscopy (JPS-9200, JEOL, Mg K $\alpha$ ), Fourier transform infrared spectroscopy (FTIR; Nicolet 6700), and thermal gravimetric mass spectrometry (TGMS; Rigaku). The local structure of the complex in aqueous solution was studied with extended X-ray absorption fine structure (EXAFS; Aichi Synchrotron center).

\subsection{Analysis of the dispersion state of SWCNT}

The Zeta potential changes of the SWCNT dispersions at different concentrations of $\mathrm{Zn} / \mathrm{Al}$ complex, from 0.001 to $1.000 \mathrm{wt} . \%$, and at constant SWCNT concentration of $0.002 \mathrm{wt} . \%$ were measured with a Nicomp 380 ZLS at a laser intensity of $300 \mathrm{kHz}$. Raman spectra were recorded using an inVia Raman microscope (IAB 8303) at an excitation wavelength of $735 \mathrm{~nm}$ and $532 \mathrm{~nm}$. The nanotubes were observed by a High-Resolution Transmission Electron Microscope (HRTEM), JEOL JEM 2100.

\section{Results and discussion}

\subsection{Zn/Al complex and surfactants in the dispersion of SWCNT}

Dispersion of SWCNT obtained using the $\mathrm{Zn} / \mathrm{Al}$ complex is similar to the dispersion of SWCNT dispersed with surfactants. The $\mathrm{Zn} / \mathrm{Al}$ complex does not form any foam after shaking, while the surfactants generate a stable foam as shown in Fig. 1. 


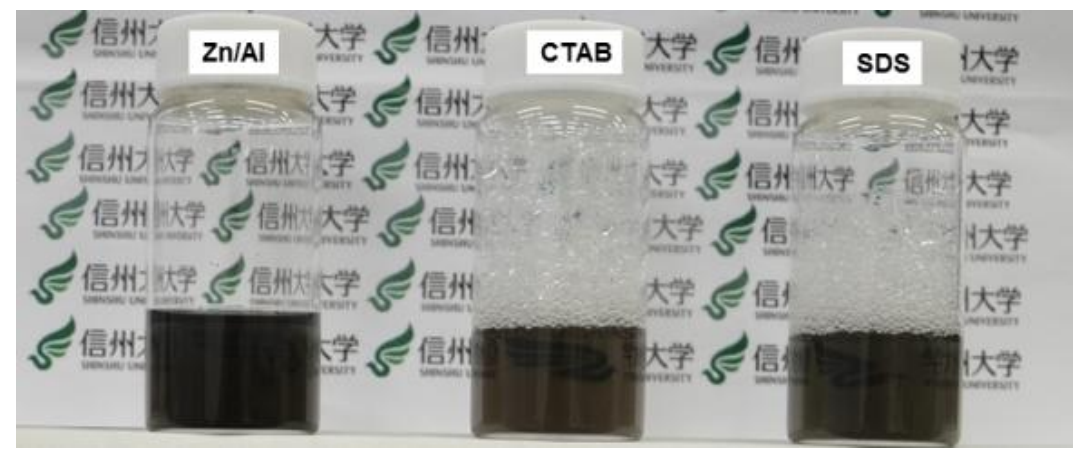

Figure 1. SWCNT dispersed in water with $\mathrm{Zn} / \mathrm{Al}$ complex and the two types of surfactants, CTAB and SDS, after shaking.

The $\mathrm{Zn} / \mathrm{Al}$ complex induces incredibly high stability to SWCNT, thus, it can be stably dispersed for hours, days, months, or up to one year as we have examined so far Fig 2.

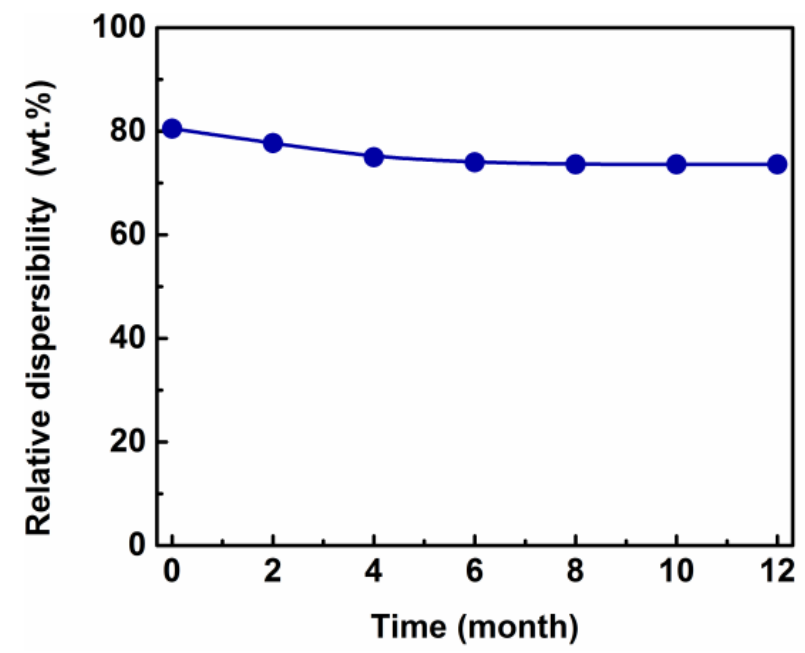

Figure 2. The relative dispersibility of SWCNT vs. age. The relative dispersibility diminishes about $6 \mathrm{wt} . \%$ after three months and does not change thereafter for nine months.

Fig. 3a shows the relative dispersibility of SWCNT dispersed with Zn/Al complex, cetyl trimethylammonium bromide (CTAB), and sodium dodecyl sulfate (SDS). The relative dispersibility maximum of SWCNT dispersed with the surfactants is more than five times larger than the relative dispersibility maximum of SWCNT dispersed with the Zn/Al complex. This suggests that the $\mathrm{Zn} / \mathrm{Al}$ complex is highly efficient at dispersing SWCNT in comparison with surfactants. Dispersibility of SWCNT in aqueous solution sensitively depends on the composition of the $\mathrm{Zn} / \mathrm{Al}$ complex. Pure components of $\mathrm{Zn}\left(\mathrm{CH}_{3} \mathrm{COO}\right)_{2}$ and $\mathrm{Al}\left(\mathrm{NO}_{3}\right)_{3}$ cannot act as dispersants for SWCNT in aqueous media, while a bimetallic $\mathrm{Zn} / \mathrm{Al}$ complex shows 
remarkable dispersibility at a molar fraction of $\mathrm{Zn}$ in the range of 0.5 0.9 (Fig. 3b); the composition of $\mathrm{Zn} / \mathrm{Al}$ yielding the highest dispersibility is 0.66 . The molar ratio of $\mathrm{Zn} / \mathrm{Al}$ giving the highest dispersibility corresponds to the stoichiometric ratio of $\mathrm{Zn} / \mathrm{Al}$ for the synthesis of the complex (Fig. S4). This indicates that a $\mathrm{Zn} / \mathrm{Al}$ complex of a definite structure is key to dispersing SWCNT stably.

(a)

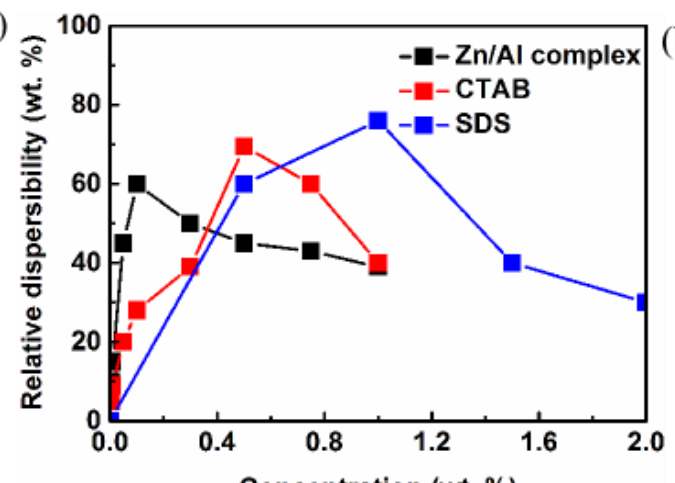

(c)

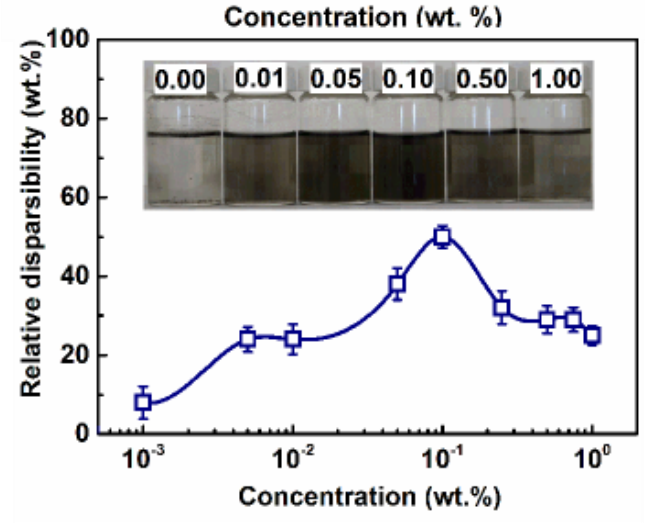

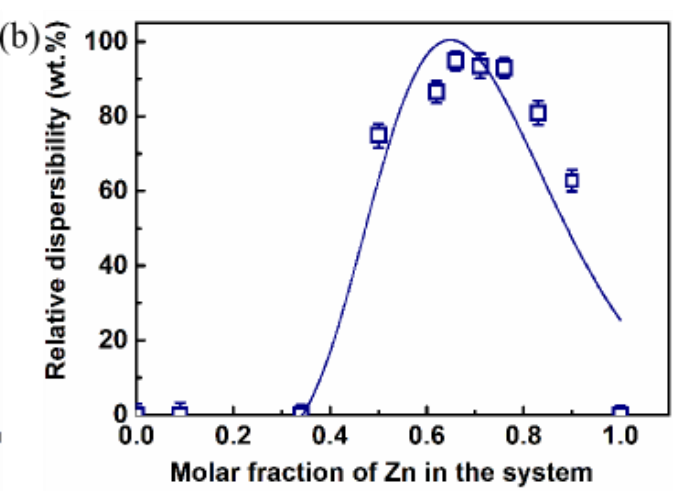

(d)

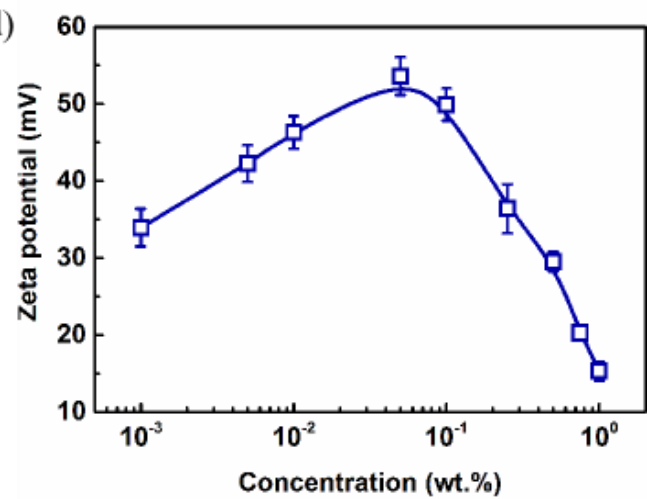

Figure 3. (a) Comparative study of the relative dispersibility of SWCNT vs. concentration of $\mathrm{Zn} / \mathrm{Al}$ complex, CTAB, and SDS. (b) Relative dispersibility of SWCNT vs. the molar fraction of $\mathrm{Zn}$ in $\mathrm{Zn} / \mathrm{Al}$ complex and (c) concentration of $\mathrm{Zn} / \mathrm{Al}$ complex in the dispersion system. (d) Zeta potential of SWCNT dispersion against the concentration of $\mathrm{Zn} / \mathrm{Al}$ complex. Here, all samples were characterized after centrifugation at $4000 \mathrm{rpm}$ for $20 \mathrm{~min}$, except for the sample in Fig. $3 \mathrm{~b}$.

Dispersibility of SWCNT strongly depends on the concentration of the $\mathrm{Zn} / \mathrm{Al}$ complex (Fig. 3c). Relative wt.\% of the stably dispersed SWCNT gradually increases with the concentration up to $0.10 \mathrm{wt} . \%$ and then decreases. Fig. $3 \mathrm{~d}$ shows the dependence of the zeta potential on the concentration of the $\mathrm{Zn} / \mathrm{Al}$ complex. Importantly, the zeta potential dependence briefly agrees with the dispersibility vs. concentration of the $\mathrm{Zn} / \mathrm{Al}$ complex. The dispersibility is maximized at $0.10 \mathrm{wt} . \%$, which can be assigned to the uniform adsorption of $\mathrm{Zn} / \mathrm{Al}$ complex per 
unit surface area of SWCNT, exhibiting a positive charge of $+55 \mathrm{mV}$. A highly positive zeta potential value indicates that SWCNT is stabilized due to electrostatic repulsive interactions [22]. Below $0.10 \mathrm{wt} . \%$, the amount of $\mathrm{Zn} / \mathrm{Al}$ complex is insufficient to coat the surface of SWCNT completely, exhibiting lower dispersibility. Above $0.10 \mathrm{wt} . \%$, SWCNT precipitate due to high loading of $\mathrm{Zn} / \mathrm{Al}$ complex onto their surface, leading to destabilization and partial precipitation.

\subsection{The structure of $\mathrm{Zn} / \mathrm{Al}$ complex}

In order to better understand the mechanism of SWCNT dispersion, structural determination of the $\mathrm{Zn} / \mathrm{Al}$ complex is of crucial importance. The amorphous nature of the $\mathrm{Zn} / \mathrm{Al}$ complex was confirmed by XRD (Fig. S5). The local structure around Zn was examined with EXAFS, while the structure around Al was investigated with XPS. Fig. 4a and b show the Fourier transform (FT) and $\mathrm{k}^{3}$-weighted EXAFS signals for $\mathrm{Zn}$ of the $\mathrm{Zn} / \mathrm{Al}$ complex in solid and liquid phases and $\mathrm{Zn}\left(\mathrm{CH}_{3} \mathrm{COO}\right)_{2}$ as a reference as well. The intense signal in FT corresponds to the $\mathrm{Zn}-\mathrm{O}$ first shell distance, suggesting that $\mathrm{Zn}$ is coordinated with $\mathrm{O}$. The coordination number of $\mathrm{Zn}$ and the bond length between $\mathrm{Zn}$ and $\mathrm{O}$, obtained by fitting EXAFS data, are shown in Table S1. The coordination number of $\mathrm{Zn}$ increased up to 5.8 upon formation of the $\mathrm{Zn} / \mathrm{Al}$ complex in aqueous solution. Thus, $\mathrm{Zn}$ was presented in the form of a $\mathrm{Zn}^{2+}$ ion hydrated with 6 molecules of $\mathrm{H}_{2} \mathrm{O}$, where the distance of $\mathrm{Zn}-\mathrm{O}$ was determined to be $2.07 \AA$, corresponding to the literature value [24] of $\mathrm{Zn}^{2+}$ hydrated ions obtained by XRD analysis. Fig. 4c and d show XPS spectra of the $\mathrm{Zn} / \mathrm{Al}$ complex for $\mathrm{Al} 2 \mathrm{p}$ and $\mathrm{O} 1 \mathrm{~s}$. The peak at $75.37 \mathrm{eV}$ suggests the presence of oxidized Al, while the peak at $533.35 \mathrm{eV}$ indicates the presence of $\mathrm{O}$ covalently bound with $\mathrm{Al}$ as suggested by Bournel et al. [25]. Accordingly, the $\mathrm{Al}$ and $\mathrm{O}$ atoms were bound in the sequence $\mathrm{Al}-\mathrm{O}-\mathrm{C}$, which can be assigned to the frame structure of $\mathrm{Al}\left(\mathrm{CH}_{3} \mathrm{COO}\right)_{3} ; \mathrm{C}$ atoms of the Al-O-C structure correspond to a $\mathrm{CH}_{3} \mathrm{COO}^{-}$group (Fig. S6). These structural data lead to the conclusion that complex $\mathrm{Zn}\left(\mathrm{NO}_{3}\right)_{2}$ and amorphous $\mathrm{Al}\left(\mathrm{CH}_{3} \mathrm{COO}\right)_{3}$ are obtained by a stoichiometric reaction of the synthesis of $\mathrm{Zn} / \mathrm{Al}$ complex dispersant. The presence of hydrophilic carriers such as $\mathrm{NO}_{3}{ }^{-} \mathrm{NO}_{3}^{-}$ions and $\mathrm{CH}_{3} \mathrm{COO}$ - groups is additionally supported by FTIR and TG-mas spectra (Fig. S7a and b). 

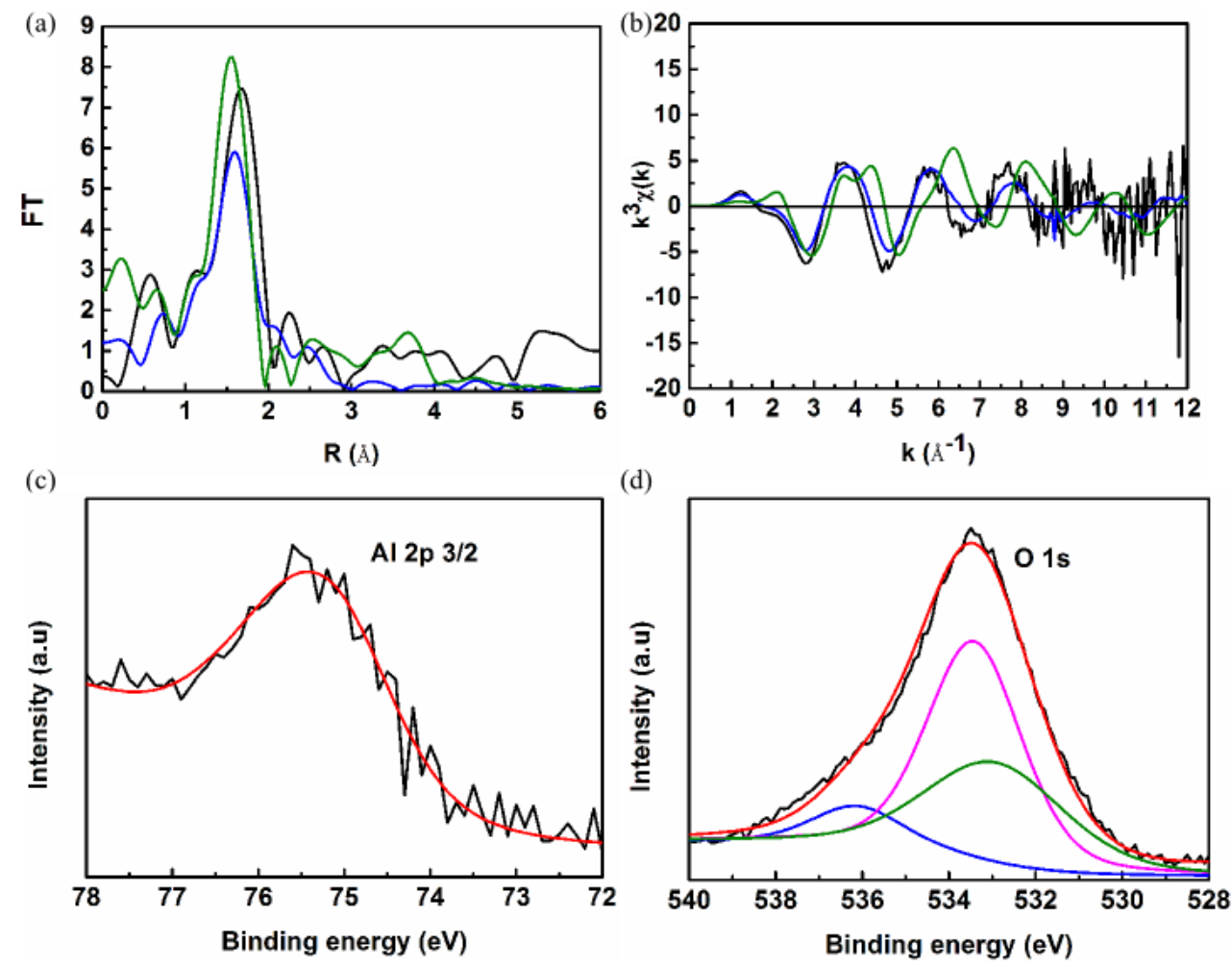

Figure 4. (a) Fourier transform (FT) and (b) $\mathrm{k}^{3}$-weighted EXAFS signals of $\mathrm{Zn} / \mathrm{Al}$ complex aqueous solution with a concentration of $0.05 \mathrm{wt} . \%$ (green line), solid $\mathrm{Zn} / \mathrm{Al}$ complex (blue line), and $\mathrm{Zn}\left(\mathrm{CH}_{3} \mathrm{COO}\right)_{2}$ (black line). (c) XPS spectra of $\mathrm{Zn} / \mathrm{Al}$ complex for $\mathrm{Al} 2 \mathrm{p}$ and (d) $\mathrm{O} 1 \mathrm{~s}$.

\subsection{The interactions between $\mathrm{Zn} / \mathrm{Al}$ complex and SWCNT and dispersion mechanism}

Thus, the $\mathrm{Zn} / \mathrm{Al}$ complex consists of $\mathrm{Al}\left(\mathrm{CH}_{3} \mathrm{COO}\right)_{3}$ acting as the amphiphilic carrier and a complex of $\mathrm{Zn}^{2+}$ and $\mathrm{NO}_{3}^{-}$ions acting as the hydrophilicity carrier; the $\mathrm{Zn} / \mathrm{Al}$ complex is amphiphilic. Since $\mathrm{Zn}\left(\mathrm{NO}_{3}\right)_{2}$ cannot disperse SWCNT in water, and $\mathrm{Al}\left(\mathrm{CH}_{3} \mathrm{COO}\right)_{3}$ gives rise to an extremely poor dispersion of SWCNT (Fig. S8), the Zn/Al complex, which bridges $\mathrm{Al}\left(\mathrm{CH}_{3} \mathrm{COO}\right)_{3}$ with $\mathrm{Zn}^{2+}$ and $\mathrm{NO}_{3}{ }^{-} \mathrm{NO}_{3}^{-}$ions, exhibits excellent amphiphilicity. Therefore, in the dispersion system, SWCNT can be embedded into the amorphous $\mathrm{Zn} / \mathrm{Al}$ complex, inducing dissociation of SWCNT bundles in water as we observed by HRTEM (Fig. 5). 

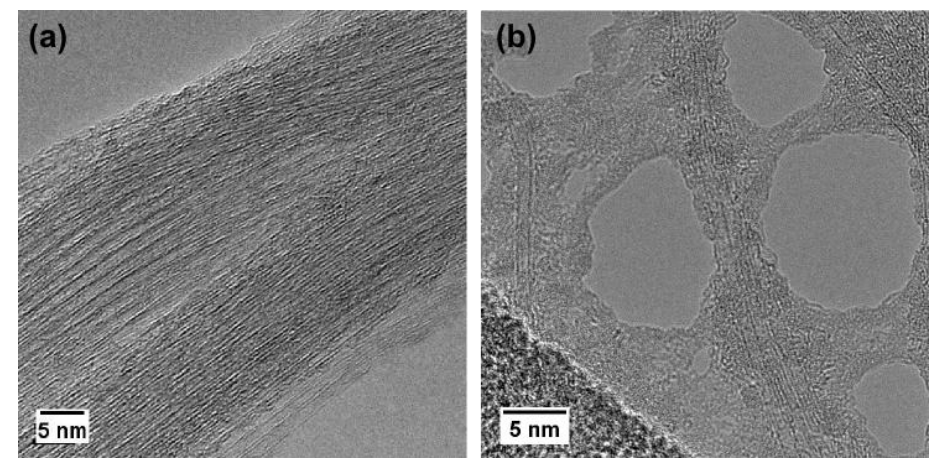

Figure 5. (a) HR-TEM images of SWCNT dispersion without Zn/Al complex and (b) with Zn/Al complex

Highly stable dispersion of SWCNT indicates high affinity of $\mathrm{Zn} / \mathrm{Al}$ complexes for SWCNT, whose interactions were studied by optical absorption and Raman spectroscopy. Direct evidence of a charge transfer interaction between Zn/Al complexes and SWCNT can be observed in Fig. 6. For pristine SWCNT, we observed three characteristic peaks at $0.63 \mathrm{eV}, 1.18 \mathrm{eV}$, and $1.62 \mathrm{eV}$, corresponding to S11, S22, and M11 transitions, respectively [14,26]. However, in the presence of the $\mathrm{Zn} / \mathrm{Al}$ complex, the peak at $0.63 \mathrm{eV}$ corresponding to the $\mathrm{S} 11$ transition cannot be observed, suggesting that valence electrons are depleted from SWCNT [14] due to a charge transfer interaction between them and the $\mathrm{Zn} / \mathrm{Al}$ complex; the complex acts as an electron acceptor. S22 and M11 bands are slightly shifted, suggesting a charge transfer interaction as well.

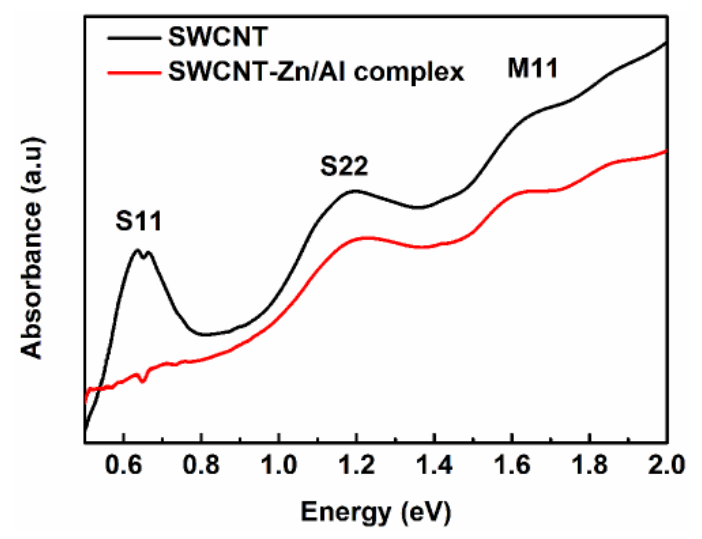

Figure 6. Optical absorption spectra of SWCNT and SWCNT-Zn/Al complex recorded in the film form.

Raman spectroscopic examination also supports the presence of a charge transfer interaction at the metallic and semiconducting nanotubes. Metallic nanotubes were excited at 785 
$\mathrm{nm}$, showing interesting features of RBM and G-band, Fig. 7a and b. The intensity of the RBM band decreases markedly with the increase of the concentration of the $\mathrm{Zn} / \mathrm{Al}$ complex. In particular, the depression of the band at $172.6 \mathrm{~cm}^{-1}$ is more remarkable than that at $161.5 \mathrm{~cm}^{-1}$. The intensity depression should come from the severe suppression of the RBM vibration due to the adherence of the dispersant on the SWCNT surface. On the other hand, the G-band change is more drastic. SWCNT without dispersant have a distinct doublet structure consisting of $\mathrm{G}^{-}$at $1568.3 \mathrm{~cm}^{-1}$ and $\mathrm{G}^{+}$at $1591.1 \mathrm{~cm}^{-1}$. The G-band is blue-shifted by $16 \mathrm{~cm}^{-1}$, suggesting a charge transfer from the nanotubes to the $\mathrm{Zn} / \mathrm{Al}$ complex [27,28]. Semiconducting nanotubes were excited at $532 \mathrm{~nm}$, Fig. 7c and d. The tendency of the depression of RBM band and shift of Gband with the increase of the concentration of $\mathrm{Zn} / \mathrm{Al}$ complex is similar to the metallic nanotubes. However, the intensity change of the RBM and blue-shift of the G-band is less significant, indicating that semiconducting SWCNT have smaller affinity for Zn/Al complex than metallic SWCNT.

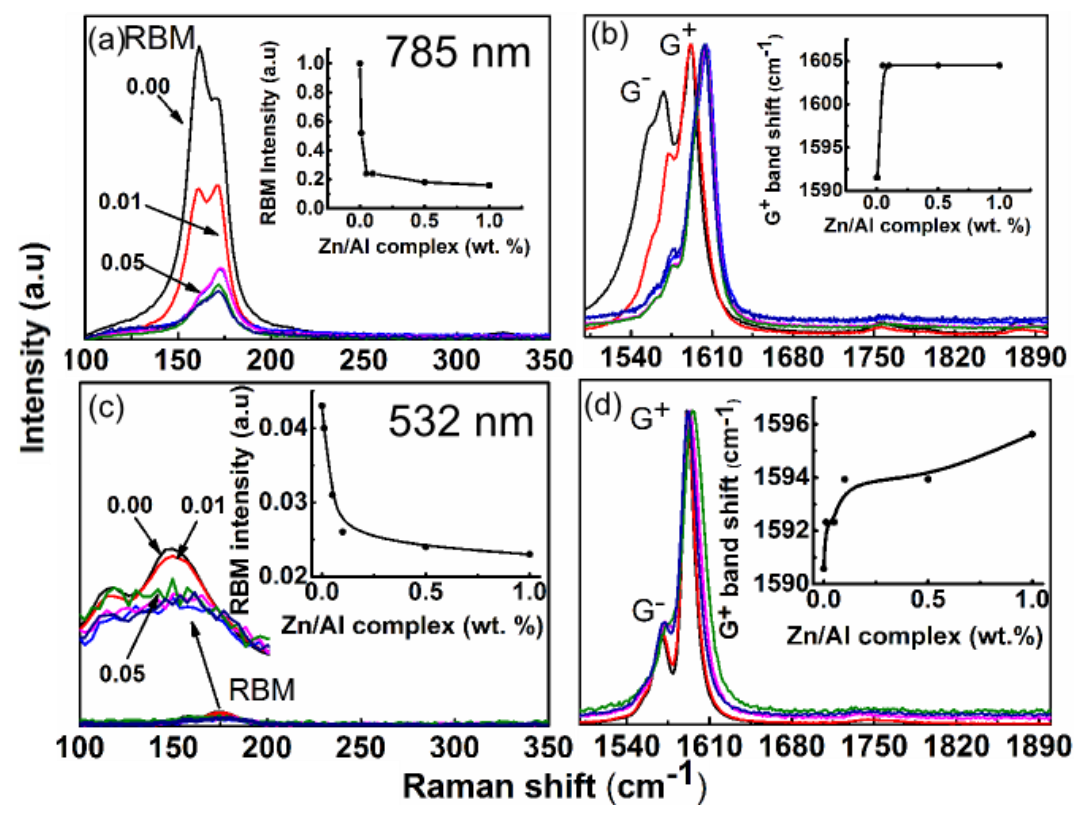

Figure 7. Raman spectra of the metallic and semiconducting SWCNT dispersed using Zn/Al complex. (a) The RBM and (b) G-band of the metallic SWCNT was recorded at the laser wavelength of $785 \mathrm{~nm}$; (c) the RBM and (d) G-band of the semiconducting SWCNT was recorded at the laser wavelength of $532 \mathrm{~nm}$. 
The charge transfer interaction can be attributed to the presence of the $\mathrm{Al}$ atoms, whose species have a tendency to act as electron acceptors [29], suggesting their presence on the surface of SWCNT. Hence, the molecules of $\mathrm{Al}\left(\mathrm{CH}_{3} \mathrm{COO}\right)_{3}$ were strongly adsorbed onto the surfaces of SWCNT via $\mathrm{Al}$ atoms, which possess hydrophobicity as shown in Fig. 8. The $\mathrm{Zn}^{2+}$ and $\mathrm{NO}_{3}^{-}$ $\mathrm{NO}_{3}^{-}$ions are then electrostatically bound to such coated SWCNT, inducing a charge on their surface. Since a positive charge is detected, we assume that $\mathrm{Zn}^{2+}$ ions should be present in the outer layer of SWCNT, inducing a highly positive charge to the SWCNT surface. Zeta potential was measured to be $+55 \mathrm{mV}$. A higher zeta potential value indicates a higher stability of the SWCNT dispersion; the magnitude of zeta potential should be greater than $\pm 15 \mathrm{mV}$ for the electrostatic stabilization of the colloidal dispersions. Conventional surfactants such as Dowfax 3B2, SDS, CTAB and NaDBS have large magnitudes of the zeta potential of $-97,3-79,3+61,5$ and $-60,4 \mathrm{mV}$, respectively. [22] Such a large magnitude of zeta potential arises from the high degree of packing of SWCNT surface with the surfactant molecules; the higher degree of packing, the more difficult to remove the surfactant from the SWCNT surface in a dry state. This feature is important in the transparent and conducting film fabrication, where it is necessary to remove dispersants from the surface of film in order to improve the opto-electronic properties. Thus, the $\mathrm{Zn} / \mathrm{Al}$ complex has relatively large zeta potential, which is slightly lower in comparison with the surfactants, guaranteeing a high stability of the SWCNT aqueous dispersion and easy removability from the SWCNT surface as well.

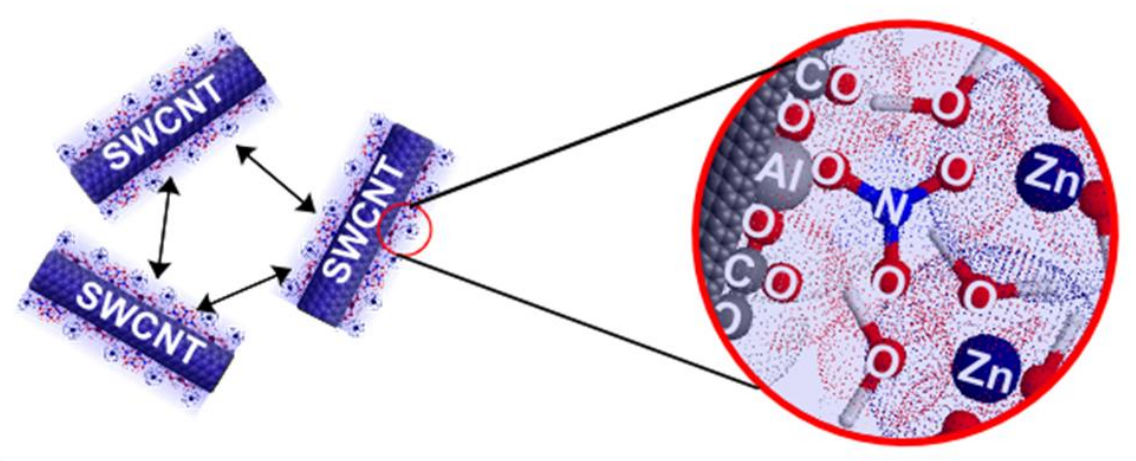

Figure 8. The mechanism of SWCNT dispersion stabilized by Zn/Al complexes. The surface of the nanotube is coated with $\mathrm{Al}\left(\mathrm{CH}_{3} \mathrm{COO}\right)_{3}$ via $\mathrm{Al}$ atoms in the first layer, while the second layer is composed of $\mathrm{Zn}^{2+}$ and $\mathrm{NO}_{3}^{-}$ions. 
To examine the importance of surface charge on the dispersibility of SWCNT, we conducted a series of experiments of relative dispersibility and zeta potential versus $\mathrm{pH}$, Fig 9a and $b$. The relative dispersibility of SWCNT is closely related to the $\mathrm{pH}$ of the dispersion system. At a $\mathrm{pH}$ below 2, zeta potential was diminished to $-3 \mathrm{mV}$, indicating that $\mathrm{Zn} / \mathrm{Al}$ complexes were dissolved from SWCNT surfaces, showing the surface charge of the intrinsic SWCNT [30]. The dissolution of $\mathrm{Zn} / \mathrm{Al}$ complexes caused complete precipitation of SWCNT. On the other hand, at a $\mathrm{pH}$ above $6.5, \mathrm{Zn} / \mathrm{Al}$ complexes were transformed into $\mathrm{Al}$ jelly structures that cannot act as dispersants for SWCNT, causing their precipitation. Therefore, there is a certain range of the $\mathrm{pH}$ values, from 3.8 to 6.8 at which the $\mathrm{Zn} / \mathrm{Al}$ complex is preserved of the chemical changes, acting as the dispersant for SWCNT.
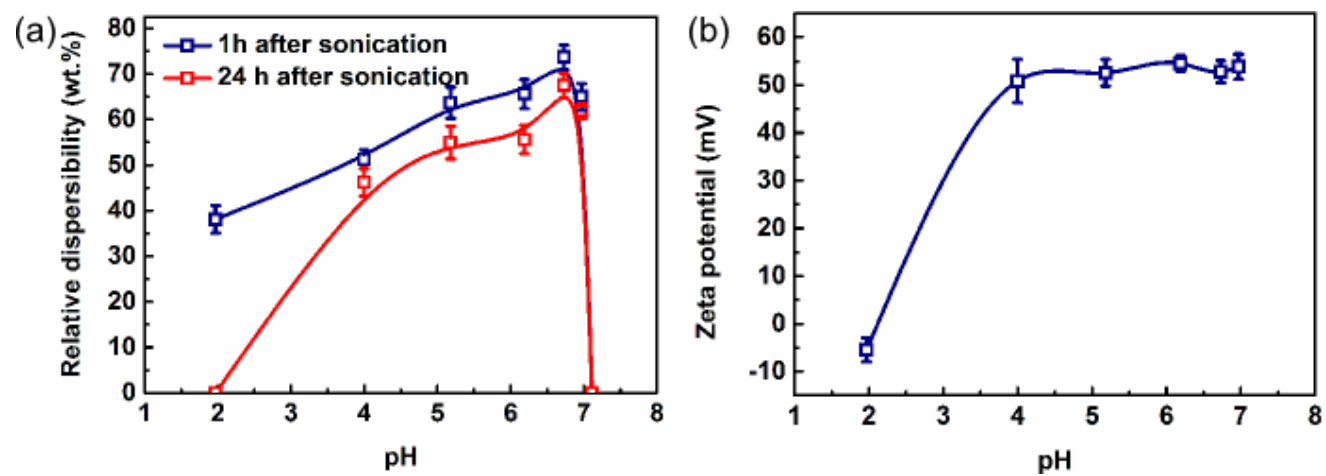

Figure 9. (a) Relative dispersibility and (b) zeta potential dependence of SWCNT aqueous dispersion vs. $\mathrm{pH}$.

\section{Conclusions}

Here, we showed a foam-free bimetallic $\mathrm{Zn} / \mathrm{Al}$ complex dispersant for dispersing SWCNT in aqueous media whose dispersion efficiency is much higher than those of CTAB and SDS. The $\mathrm{Zn} / \mathrm{Al}$ complex was synthesized from $\mathrm{Zn}\left(\mathrm{CH}_{3} \mathrm{COO}\right)_{2}$ and $\mathrm{Al}\left(\mathrm{NO}_{3}\right)$, with coupling at a molar fraction of $\mathrm{Zn}$ to $\mathrm{Al}$ of 0.66 . The $\mathrm{Zn} / \mathrm{Al}$ complex is stable and can be preserved in powder form; it can be used to disperse SWCNT in water just after quick dissolution. The $\mathrm{Zn} / \mathrm{Al}$ complex containing amorphous $\mathrm{Al}\left(\mathrm{CH}_{3} \mathrm{COO}\right)_{3}, \mathrm{Zn}^{2+}$, and $\mathrm{NO}_{3}^{-} \mathrm{NO}_{3}^{-}$ions is strongly adsorbed onto the surfaces of the SWCNTs, leading to their stabilization. Optical absorption demonstrated a charge transfer interaction between $\mathrm{Zn} / \mathrm{Al}$ complexes and SWCNT, which should cause a positive zeta potential; the observed highly stable dispersion of SWCNT in water comes from electrostatic repulsion with a zeta potential of $+55 \mathrm{mV}$. The $\mathrm{Zn} / \mathrm{Al}$ complex is a potential 
candidate for the fabrication of transparent and conducting films as well as hybrid materials based on SWCNT-Zn/Al species.

\section{Acknowledgments}

This research was supported by a grant from Development of Innovative Carbon Nanotube Composite Materials for a Low Carbon Emission Society NEDO, Japan. The EXAFS measurements were supported by Aichi Synchrotron Radiation Center.

\section{References}

[1] Ijima S. Helical microtubules of graphitic carbon. Nature 1991;354 (7): 56-58.

[2] Bandaru PR. Electrical Properties and Applications of Carbon Nanotube Structures. J Nanosci Nanotechnol 2007;7:1239-67.

[3] Salvetat JP, Bonard JM, Thomson NH, Kulik AJ, Forro L, Benoit W et al. Mechanical properties of carbon nanotubes. Appl Phys A Mater Sci Process 1999;69:255-60.

[4] Ruoff RS, Lorents DC. Mechanical and Thermal Properties of Carbon Nanotubes. Carbon 1995;33:925-30.

[5] O'Connell MJ, Bachilo SM, Huffman CB, Moore VC, Strano MS, Haroz EH et al. Band gap fluorescence from individual single-walled carbon nanotubes. Science 2002;297:5936.

[6] Dumlich H, Gegg M, Hennrich F, Reich S. Bundle and chirality influences on properties of carbon nanotubes studied with van der waals density functional theory. Phys Status Solidi Basic Res 2011;248:2589-92.

[7] Vaisman L, Wagner HD, Marom G. The role of surfactants in dispersion of carbon nanotubes. Adv Colloid Interface Sci 2006;128-130:37-46. 
[8] Shin JY, Premkumar T, Geckeler KE. Dispersion of single-walled carbon nanotubes by using surfactants: are the type and concentration important? Chem Eur J 2008;14:6044-8.

[9] Park C, Ounaies Z, Watson KA, Crooks RE, Smith J, Lowther SE et al. Dispersion of single wall carbon nanotubes by in situ polymerization under sonication. Chem Phys Lett 2002;364:303-8.

[10] Cohen RS, Roth EN, Baskaran E, Kalisman YL, Szleifer I, Rozen RY, Selective Dispersion of Single-Walled Carbon Nanotubes in the Presence of Polymers $\square$ : the Role of Molecular and Colloidal Length Scales. J Am Chem Soc 2004:14850-7.

[11] Wang Y, Iqbal Z, Mitra S. Rapidly functionalized water-dispersed carbon nanotubes at high concentration. J Am Chem Soc 2006;128:95-9.

[12] Chaisalee R, Soontravanich S, Yanumet N, Scamehorn JF. Mechanism of antifoam behavior of solutions of nonionic surfactants above the cloud point. J Surfactants Deterg $2003 ; 6: 345-51$.

[13] Denkov ND. Mechanisms of foam destruction by oil-based antifoams. Langmuir 2004;20:9463-505.

[14] Niyogi S, Hamon MA, Hu H, Zhao B, Bhowmik P, Sen R, Itkins ME et al. Chemistry of Single-Walled Carbon Nanotubes. Acc Chem Res 2002;35:1105-13.

[15] Chichak KS, Star A, Altoé MVP, Stoddart JF. Single-walled carbon nanotubes under the influence of dynamic coordination and supramolecular chemistry. Small 2005;1:452-61.

[16] Prevoteau A, Soulie C, Leibler L. Universally Dispersible Carbon Nanotubes. J Am Chem Soc. $2012 ; 134: 19961-4$.

[17] Matsuda T, Minami D, Khoerunnisa F, Sunaga M, Nakamura M, Utsumi S et al. Aqueous Nanosilica-Dispersants for Carbon Nanotube. Langmuir 2015;31:3194-202. 
[18] Brinker CJ and Scherer GW. Sol-gel science: the physics and chemistry of sol-gel processing. 1990.

[19] Livage J, Henry M, Sanchez C. Sol-gel chemistry of transition metal oxides. Prog Solid St Chem 1988.

[20] Uekawa N, Kaneko K. Dopant Reduction in p-Type Oxide Films upon Oxygen Absorption. J Phys Chem 1996;100:4193-8.

[21] Uekawa N, Kaneko K. Transition metal oxide films. Adv Mater 1995;7:312-5.

[22] White B, Banerjee S, O’Brien S, Turro NJ, Herman IP. Zeta-Potential Measurements of Surfactant-Wrapped Individual Single-Walled Carbon Nanotubes. J Phys Chem C 2007;111:13684-90.

[23] Szabó A, Perri C, Csato A, Giordano G, Vuono D, Nagy JB. Synthesis Methods of Carbon Nanotubes and Related Materials. Materials 2010;3:3092-140.

[24] Marcus Y. Ionic radii in aqueous solutions. J Solution Chem 1983;12:271-5.

[25] Bournel F, Laffon C, Parent P, Tourillon G. Adsorption of acrylic acid on aluminium at 300 K: a multi-spectroscopic study. Surf Sci 1996;352-354:228-31.

[26] Hamon MA, Itkins ME, Niyogi S, Alvaraez T, Kuper C, Menon M. Effect of rehybridization on the electronic structure of single-walled carbon nanotubes. J Am Chem Soc 2001;123:11292-3.

[27] Rao AM, Eklund PC, Bandow S, Thess A, Smalley RE. Evidence for charge transfer in doped carbon nanotube bundles from Raman scattering. Science (80) 1997;191:257-9.

[28] Geng HZ, Kim KK, So KP, Lee YS, Chang Y, Lee YH. Effect of acid treatment on carbon nanotube-based flexible transparent conducting films. J Am Chem Soc 2007;129:7758-9. 
[29] Burova MV, Fionov AV, Tveritinova EA, Kharlanov AN, Lunin VV.The electron acceptor and catalytic properties of zirconium dioxide modified with aluminum and gallium oxides. Russ J Phys Chem A 2007;81:164-9.

[30] Sun Z, Nicolosi V, Rickard D, Bergin DS, Aherne D, Coleman JN. Quantitative Evaluation of Surfactant-stabilized Single-walled Carbon Nanotubes: Dispersion Quality and Its Correlation with Zeta Potential. J Phys Chem C 2008;112:10692-9. 